\title{
The Undergraduate Ambassadors Scheme in Ireland
}

\author{
MARIA MEEHAN
}

\begin{abstract}
In this article I will briefly describe the Undergraduate Ambassadors Scheme which has been running in the UK since 2002. This scheme provides university departments with a framework for running a module that awards academic credit to undergraduates for developing transferable skills, while working with teachers in local schools. I will explain why I chose to coordinate an Undergraduate Ambassadors Scheme module in mathematics in University College Dublin and discuss what is involved in setting-up, running, and assessing such a module.
\end{abstract}

\section{INTRODUCTION}

The Undergraduate Ambassadors Scheme (UAS) first started in the United Kingdom in 2002. The scheme was founded by Simon Singh and Hugh Mason out of a concern over teacher shortages in mathematics, science and technology, and the declining number of university applicants to these subject areas. The basic idea behind the UAS is that undergraduate students gain academic credit for developing their transferable skills, while working with a teacher in a local school. The scheme has grown rapidly since 2002 when 28 students from four university departments took part. In the academic year 2007-2008, 107 departments from 41 universities across the UK and Ireland participated in the scheme - with the School of Mathematical Sciences, University College Dublin (UCD) offering a UAS Module to its undergraduates this year for the first time.

In this article, I will explain why I chose to coordinate a UAS module in mathematics in UCD and discuss what is involved in settingup, running, and assessing a module of this kind. It is my hope that should a colleague want to offer a similar module to his or her undergraduate students, this article will act as a check-list of some of the main issues to be considered. 


\section{Why Offer a UAS Module?}

In 2004, on reading an article by Ray d'Inverno and Paul Cooper in Educational Studies in Mathematics [2], I decided that a UAS module was something I'd like to introduce in UCD. In this article the authors describe setting-up and running one of the first UAS modules in 2002 at the University of Southampton. (For the interested reader, there are some additional articles written on the scheme $[1$, $3,4]$.)

My main motivation for offering a UAS module in mathematics was because of the benefits it offers the final-year undergraduate student. Firstly, it gives the undergraduate a chance to explore a career in teaching by giving him or her the opportunity of gaining some experience in the classroom before graduation. Each year, a number of final year students on the BA in Mathematical Studies Degree in UCD apply for a place on a Postgraduate Diploma in Education (PGDE). The UAS module can give them the chance to decide if this is right graduate programme for them. The module might also encourage undergraduates, who may not already have done so, to seriously consider a career in teaching. We need enthusiastic, interested, well-qualified mathematics teachers in our second-level schools and this module has the potential to help address this issue, if only in a small way.

Secondly, the student gains academic credit for developing his or her key transferable skills. These can include communication and presentation skills; the ability to work in a team; to manage time and prioritise; to improvise and take initiative when appropriate; to give and receive feedback; and to critically reflect on one's strengths and weaknesses. A skill I place particular importance on in the UCD module, is the ability to communicate mathematics effectively to others. Every mathematics department wants its graduates, not just to have good mathematical knowledge, but to present well in interviews and to act professionally in the workplace. For this reason I feel, as mathematics lecturers, we cannot ignore the issue of how we might help our undergraduates develop these key skills.

Of course the undergraduate student is not the only stakeholder in this module - the second-level mathematics teachers and students, along with the mathematics department and the university, should also benefit from taking part. Benefits to the second-level teacher 
might include teaching assistance in a large class; support in providing additional assistance to students at either end of the ability spectrum; support in providing after-school activities such as mathematics study groups; lasting classroom resources as a result of the undergraduate's Special Project; and links with mathematicians at a local university. For the second-level students, benefits from taking part in the module might include the opportunity to gain individual or small-group mathematics support; to avail of after-school mathematics support; and to learn about mathematics and university life from an enthusiastic undergraduate. University departments have the potential to benefit from having more confident, employable, professional graduates; from creating and maintaining links with local second-level schools; and from an improvement in the number of students entering undergraduate degrees in mathematics (perhaps!).

\section{Setting-up a UAS Module}

I took advantage of the introduction of modularisation to UCD in order to offer MST30060-Undergraduate Ambassadors Scheme in Mathematics - as an optional or elective module to final year BA in Mathematical Studies students in the second semester of the academic year 2007-2008. I would not advocate making a module of this nature compulsory or core for all final year mathematics undergraduates - placing a student with a bad attitude or poor people skills in a local school, could do immense harm to the scheme and reflect very badly on the mathematics department.

And so it was, that in September 2007, I found myself drawing up a list of things I needed to do before students embarked on the module in January 2008. I had three immediate concerns: firstly, I needed to find schools and teachers willing to take part; secondly, I needed to find suitable undergraduates who wanted to enrol on the module; and thirdly, I had to find out if my students needed Garda Clearance in order to work with children under 18. I will now address each of these in turn.

In order to find teachers and schools willing to take part, I contacted the UCD New ERA Office who run the widening participation programme in UCD. By planning interventions at the primary and second level in local government designated-disadvantaged schools, the New ERA Office aims to encourage more students from sociallydisadvantaged backgrounds to consider obtaining a third-level education. Fiona Sweeney and Michelle King from this office were very 
keen to have some of these schools participate in the UAS module. Of the 18 schools contacted, 14 wanted to participate and each wrote a short paragraph explaining why. In most cases, the schools were keen to host an undergraduate in order to provide additional mathematics support for their Junior and Leaving Certificate students at either end of the ability spectrum.

With 14 schools willing to participate, I then needed to find suitable undergraduates who wanted to enrol in the module. Any finalyear Mathematical Studies student interested in taking part had to complete and submit an application form by 5 October. On the application form, students had to explain why they wanted to take part in the module, and to describe any relevant experience they had that might benefit them on the module. I received nine applications - just under half the class.

All nine students were invited to interviews which were held in mid-October. Each interview lasted approximately 15 minutes, and was jointly conducted by the module tutor, Cathy Paolucci, and me in as formal an atmosphere as possible in order to make the experience more realistic for the student. Based on their application forms, interviews, and mathematics grades, six students were offered places on the module. All accepted and were officially enrolled.

One criticism at this point may be that it was not worth offering this module, if only six students were taking it. However, given that I was running it for the first time, I wanted to treat the module more as a pilot project. In the coming year, I would hope to double the number of students on the module.

Now that I had six undergraduates, I needed to chose six schools from the fourteen that wanted to participate. Primarily I made the decision based on the proximity of the school from UCD, and access to the school from the university on public transport. However, one student did agree to go to a school in Killinarden near Tallaght, another went to Ballyfermot, and yet another to Bray. It is important to consider whether the undergraduate has a car, when assigning him or her to a particular school.

At the start of November, I visited each school and spoke to the host mathematics teacher. While this was time-consuming, I wanted to meet each teacher face-to-face in order to establish a working relationship with him or her. Ray d'Inverno, the Director of the UAS in the UK, has suggested that the teachers could all be invited into the university for a presentation and lunch, and this might be more 
practical in the future should the number of schools participating increase. I asked each teacher what advice I should give the undergraduates before entering the school, and I received some great suggestions which were then incorporated into the UAS Handbook and training day materials.

My third concern at the start of the semester had been in relation to Garda Clearance. Since 2006, Garda vetting has become a condition of employment for new teachers and appointees who have unsupervised access to children and vulnerable adults (see the website at www.teachingcouncil.ie). One cannot apply directly to the Garda Central Vetting Unit - there is usually a contact person in each university through which all applications must be submitted. The UCD contact supplied me with the application forms and advised me that they can take up to three months to be processed. In our case, it took four.

By mid-November, my three concerns had been addressed - each undergraduate was assigned to a school and had submitted a Garda vetting application form. The UAS in the UK advise that the undergraduates attend a training day before they enter the schools. Consequently, two training sessions for the undergraduates were arranged from $5-8 \mathrm{pm}$ on the first two days of the second semester. All was now in order until after Christmas!

\section{UAS Training Sessions and Handbook}

At the start of January I had to think about what should be included in the training sessions, and about developing an accompanying handbook, which would act both as a training and resource manual. Here the UAS website (www.uas.ac.uk) proved to be an excellent starting point as one can access and edit a number of handbooks and materials already developed by others. With the UAS handbook as a template, Cathy and I developed a handbook more suitable for the Irish context. It contains five chapters. After a brief introduction to the UAS in Chapter 1, the second chapter entitled What's Involved in the UAS Module? describes the learning outcomes of the module, and elaborates on how the module will be assessed.

A key point about the assessment of this module, is that students simply don't get an A+ because they have spent 20-30 hours working in a local school. They are assessed on whether or not they 
have achieved the learning objectives, which in the case of the UCD module were as follows:

On completion of this module the student should be able to provide evidence of how he or she has:

- Communicated mathematics effectively to others;

- Developed key transferable skills.

Evidence is provided by the undergraduate in a reflective journal that is kept throughout the semester (worth 30\%); a final report of 2,000 words to be submitted at the end of the semester (worth $30 \%$ ); and a 15-minute presentation held during the last week of the semester (worth 30\%). The final 10\% is awarded by the host teacher who writes a few lines of feedback on each student and gives him or her a mark out of 10 .

Given that the typical mathematics undergraduate may not be used to these forms of assessment, an hour and a half of the first training session was spent outlining the learning objectives of the module and what was expected from each assessment. An additional part of the assessment required each undergraduate to design a Special Project for use in the school, and to describe this in the final report. Some time in the training session was spent discussing what might be involved in a Special Project.

An hour and a half of the second training session was spent covering the material in Chapters 3 and 4 of the handbook. Chapter 3 Second-level Mathematics Education in Ireland - describes the Irish second-level education system, and outlines current issues in secondlevel mathematics education in this country. Chapter $4-$ The Classroom Situation - outlines the advice given to me by the participating teachers; advises the undergraduates on how to work with the host teacher; and encourages the student to think about possible situations that may arise when working with second-level students.

Chapter 5-Teaching Mathematics - discusses points to consider when planning a mathematics lesson. During the first training session, Cathy spent an hour and a half on this topic, and during the second training session the undergraduates were asked to put the theory into practice. In pairs, they had to consider how they would plan a lesson on graphing a line, and then present the lesson to the rest of the class. This proved to be a great success, and a tremendous learning experience for the students. 
With the training sessions completed, the module had officially begun.

\section{During a UAS Module}

As the module coordinator, the demands on my time for the duration of the twelve weeks of the semester were actually quite low. Cathy and I met twice with the students to get some feedback on what type of experiences they were having in the schools, and to discuss any issues or problems which might have arisen. Mid-way through the semester, I also rang each teacher to get some initial feedback on how each student was doing. Two weeks before the semester ended, I wrote to the teachers requesting formal feedback on the undergraduates, and I also invited them to write a testimonial on their UAS experiences. The reflective journals and final reports had to be submitted by the Monday of the last week of the semester, and the presentations were arranged from $5-7 \mathrm{pm}$ on the Wednesday of the same week.

If the demands on my time during the second semester were quite low, the same could not be said of the undergraduates! They were requested to spend a minimum of 20 hours in their schools, but almost all spent more than this. All were given the opportunity to observe and assist teachers in a variety of mathematics classes, from first year through to sixth year. Most got the opportunity to teach a whole class or a subset of a class. Two of the undergraduates set-up and ran after-school study groups for Higher Level Junior and/or Leaving Certificate students. One undergraduate also taught (oneon-one) a fifth year student taking Higher Level Leaving Certificate Mathematics a complete topic from the higher level curriculum.

With regard to Special Projects, one of the undergraduates designed a mathematics quiz for first year students and ran it on an interactive whiteboard that the school had just acquired; another designed and ran a mathematics competition with a first year class; and yet another held a sudoku competition with a class. The other three undergraduates designed or developed revision packs or sessions for Junior and Leaving Certificate students.

\section{Assessing a UAS Module}

In grading the assessments, the main thing I was looking for was that the students had given serious reflection to how they had communicated mathematics to others and developed their transferable 
skills. Cathy also graded the three assessment components independently, and then we agreed on a mark. For anyone coordinating a UAS module, I feel it is essential that there is a second grader for each assessment - at least until the coordinator gains a few years of experience at grading these types of assessments.

For me the highlight of the module was the students' presentations at the end of the semester. Most of the undergraduates had little experience at making a presentation, and very few had used powerpoint before. At the start of the semester I felt that they were very nervous about this assessment component, and for that reason, I only invited the Head of the UCD School of Mathematical Sciences and the host teachers along (one teacher came). However, despite initial nervousness, the presentations were of an extremely high standard. All had mastered powerpoint, all kept within the allocated 15-minute time-slot, and the confidence, passion and enthusiasm with which they all spoke was overwhelming.

Next year, I would not invite along the host teachers as I would be afraid that an undergraduate, in all sincerity, might express a view about teaching mathematics or school discipline, which a teacher may take umbrage with. However I would invite along any undergraduate interested in taking part in the UAS the following year- the presentations would give them an idea of what to expect and, if this year's standard was anything to go by, would set the bar very high for future students.

In relation to the assessment component graded by the teacher, there was only one instance where, given the teacher's written feedback and comparing it with the written feedback from the other teachers, we felt that the undergraduate deserved a slightly higher mark out of ten and we duly altered it.

Overall, given the rigorous selection process and the small number of students chosen to take part in the module, it was not surprising that in the end, no student received an overall grade lower than $\mathrm{a}+\mathrm{B}+$.

\section{Conclusions}

From the point of view of a module coordinator, setting-up and running a UAS module for the first time requires a substantial investment of time and effort, at least in the initial year. However, the UAS website and the UAS manager in the UK, Brian Lockwood, 
proved invaluable to me in terms of providing materials and support respectively. If any colleague would like to set-up such a module, I am more than happy to send all the materials developed to anyone to use or edit as he or she wishes.

Throughout the article, I have mentioned a few things I would do differently next year, but on the whole I was quite happy with the framework that I employed. Again, I feel this is due to the shared nature of advice and materials on the UAS website - others before me had ironed out many of the major issues and difficulties with running a module of this nature.

From the perspective of the six undergraduates who took part, in an end-of-semester questionnaire all felt that participating in the module had improved their overall key/transferable skills. They were given a list of ten transferable skills, and asked to select the skills which they felt had improved as a result of the module. The results are given in Table 1 below.

\begin{tabular}{|l|c|}
\hline Transferable skill & No. of students \\
\hline Communication skills on a one-to-one basis & 6 \\
Communication skills with a group & 4 \\
Presentation skills & 5 \\
Planning skills & 4 \\
Team working & 2 \\
Time management & 5 \\
Ability to prioritise tasks & 5 \\
Ability to negotiate & 1 \\
Confidence & 5 \\
Essay/report writing & 4 \\
\hline
\end{tabular}

Table 1

Five of the six undergraduates said they were interested in a career in teaching, with two already accepted onto PGDE programmes. All six said they would recommend the module to others. In an informal discussion with the six undergraduates, they told me that the module may have involved more work than some of their other mathematics modules. However because the work was so different in nature, they really didn't mind. They also liked the fact that there was no final examination involved.

I will conclude this article with some testimonials from the undergraduates and teachers who took part: 
"I am in the final year of a Mathematical Studies degree in UCD and have always wanted to be a teacher. This module has given me the opportunity to experience first hand, what teaching mathematics at a secondary level entails and has given me an accurate idea of how much work would be involved in this career choice. I am now more certain than ever that I want to pursue a career in teaching mathematics as I have had a chance to witness, first hand, the lack of teachers in this area and the lack of understanding of maths within the classroom."

Jennifer Keeler, Undergraduate Ambassador 2008

"As a final year student who was thinking about teaching as a career, this module has been invaluable to me. The amount of knowledge I have gained could never be equalled in a lecture situation. The hands-on aspect was so beneficial. The school and I both benefited immensely."

Annette Larkin, Undergraduate Ambassador 2008

"This module gave me a great opportunity to start making the transition into the professional working world. I would strongly recommend this module to anyone interested in teaching, as it helped me develop key skills needed in the classroom."

Rebekah Holmes, Undergraduate Ambassador 2008

"We, at St. Kilian's C.S., have had a very positive first experience of the UAS. Our assigned student developed a Maths Study Club, which our students greatly enjoyed, and from which they benefited greatly. He developed revision material which the students will use while preparing for their J. Cert. examinations. There was excellent communication between the student, the facilitator, and our school which ensured that participation in the scheme was hassle-free."

Mr John Murphy, St. Kilian's CS, Bray

"St. Tiernan's greatly appreciated the interest and support given to our maths students by a young 3rd level student. Motivating our students to have the confidence to pursue maths and science at honours level is in line with our learning objectives in terms of ongoing school development planning."

Mr Declan Hughes, St. Tiernan's, Dundrum 
"[Our undergraduate] provided practical assistance by offering afterschool classes to a group of third year students sitting honours level in their Junior Cert. She also took a 5th year honours student and covered a complete topic with him over the weeks she was in the school. [She] also provided general classroom assistance which was of great benefit to the students, teachers and school."

\section{Ms Anne Brogan, Killinarden CS, Killinarden}

\section{REFERENCES}

[1] P. Cooper and R. d'Inverno, The Future of the Discipline? Mathematics and the Undergraduate Ambassadors Scheme, Journal of Mathematics Teacher Education 8 (2005), 329-342.

[2] P. Cooper and R. d'Inverno, Those who can, teach: addressing the crisis in mathematics in UK schools and universities, Educational Studies in Mathematics 56 (2-3) (2004), 343-357.

[3] S. Herkes, Undergraduate Ambassadors Scheme-progress to date, MSOR Connections, Nov. 2004, Vol. 4, No. 4, 1-4.

[4] R. d'Inverno and P. Cooper, Undergraduate Ambassadors Scheme and Communicating and Teaching Mathematics, MSOR Connections, Nov. 2003, Vol. 3, No. 4, 31-34.

\section{Maria Meehan,}

School of Mathematical Sciences,

University College Dublin,

Belfield,

Dublin 4, Ireland

maria.meehan@ucd.ie

Received on 23 May 2008 and in revised form on 8 July 2008. 